\title{
BURDEN OF INTESTINAL PARASITIC INFECTIONS AMONG CHILDREN FROM FIVE SCHOOLS IN BHAIRAHAWA, NEPAL: A COMPARATIVE CROSS-SECTIONAL STUDY
}

\author{
Shristi Raut, ${ }^{1}$ Srijan Bhattarai, ${ }^{1}$ Rita Khanal, ${ }^{1}$ Sulochana Khatiwada, ${ }^{1}$ Rajeshwar Reddy Kasarla
}

\begin{abstract}
\section{INTRODUCTION}

Intestinal parasites cause significant morbidity and mortality, particularly in the tropics including Nepal. The main objective of this study was to explore the burden of intestinal parasitic infections among children in five different primary schools in Bhairahawa, Nepal.
\end{abstract}

\section{MATERIAL AND METHODS}

This was a cross-sectional comparative study among 408 children from five schools in Bhairahawa, Nepal. Stool specimens collected in a plastic container were transported to Microbiology laboratory in Universal College of Medical Sciences Teaching Hospital (UCMS-TH) immediately. Each sample was examined macroscopically and microscopically for the evidence of parasitic infection. All samples were re-analysed by sedimentation and floatation concentration techniques one after another.

\section{RESULTS}

The overall prevalence of the parasitic infection was $46.5 \%$. The prevalence varied by the methods that included routine microscopy (23.2\%), sedimentation (41.6\%) and flotation (8.3\%). Ascaris lumbricoides was the most common (29.1\%) parasite followed by Entamoeba histolytica (6.1\%). Mixed infection was also seen in $7.8 \%$ of the samples. Factors such as children's academic year, age, religion, existing illness, household water sources, meat consumed, domestic animals at house, and recent history of taking anti-helminthics were significantly associated with the intestinal parasitic infections. Prevalence of intestinal parasitic infection was higher in public school (61.1\%) compared to private school (37\%). Male students had slightly more infections (47.3\%) than females $(45.7 \%)$.

\section{CONCLUSION}

Enteric parasitic infection was very high among the primary schools' students in Bhairahawa, Nepal. Integrating concentration techniques in routine test can help to detect most of the enteric parasites in stool specimens.

\section{KEYWORDS}

Enteric parasitic infection, Nepal, Routine microscopy, Sedimentation, Floatation

1. Department of Microbiology, Universal College of Medical Sciences and Teaching Hospital, Bhairahawa, Nepal

DOI: https://doi.org/10.3126/jucms.v9i02.41993

For Correspondence

Dr. Shristi Raut

Department of Microbiology

Universal College of Medical Sciences

Bhairahawa, Nepal

Email:rautshristi@gmail.com 


\section{INTRODUCTION}

Intestinal parasitic infections (IPIs) are endemic worldwide and have been described as the major cause of illness and diseases in human beings. ${ }^{1}$ Currently, more than 1.5 billion people that is $24 \%$ of the whole world's population are infected by soil transmitted helminths (STH). Maximum infections are observed in sub-Saharan Africa, the Americas, China and East Asia. ${ }^{2}$ Globally, more than five billion people are ill from IPIs. In Asia alone, over one million people have IPI. ${ }^{3,4}$ Nepal is one of the endemic countries for IPIs. Intestinal protozoan and helminthic infection rank the third and the fourth common intestinal infection respectively in Nepal. ${ }^{6}$

IPIs are caused by protozoans such as Giardia intestinalis, Entamoeba histolytica, Cryptosporidium spp, Microsporidia, and Cyclospora cayetanenesis,Blastocystis spp, and helminthes such as Ascaris lumbricoides, Ancylostoma duodenale, Necatar americanus, Hymenolepis nana, Taenia spp, and Trichuris trichiura. ${ }^{7}$ WHO estimates that one in every four persons hosts parasitic worms. ${ }^{8}$ Ascaris lumbricoides (20\%), Ancylostoma duodenale (18\%), Trichuris trichiura $(10 \%)$ and Entamoeba histolytica (10\%) are the most common intestinal parasitic infestations reported globally. ${ }^{9}$ Current estimates suggest that Ascaris lumbricoides can infest more than one billion and Trichuris trichiura and Ancylostoma duodenale can infest 795 and 740 million people in a year. ${ }^{9}$ Although more than one in third person in South East Asia take anti-helminthic drugs regularly; around $13 \%$ of deaths were reported to be due to parasitic infections. ${ }^{10}$

Lack of access to clean drinking water, sanitation, hygiene, poverty, illiteracy, and environmental conditions conduce to a high burden of enteric parasitic infections in South and South East Asia. ${ }^{11}$ Although a South/South East Asian population bears a high burden of the parasitic infections, they are often underreported due to their benign nature of infections. ${ }^{6}$ Person with parasitic infection can remain asymptomatic for prolonged period. About $90 \%$ of infected individuals remain asymptomatic. ${ }^{12}$ Among those who are symptomatic, they present with vomiting, diarrhoea, fever, worms in the stool, cough, sputum, skin rash and abdominal discomforts. Patients may also manifest signs of growth retardation, pneumonia, hepatobiliary and pancreatic diseases and intestinal obstruction. ${ }^{13}$ Although people of all age groups are susceptible to IPIs, primary school children are the most vulnerable group and are most frequently infected. ${ }^{1,14}$

\section{Burden of parasitic infections in children}

Globally and especially in low- and middle-income countries such as Nepal, enteric parasitic infections are responsible for causing significant morbidity and mortality among primary school children. ${ }^{15}$ Studies in different parts of Nepal in the last decade found prevalence of enteric parasitic infections range from lowest $11 \%$ to highest $83.3 \%$. $^{6,10,14-25}$

Direct stool smear examination offers many advantages over diagnostic methods for detecting intestinal parasites. If performed correctly, these phenotypic methods are sensitive, simple and economical. Advantages of concentration methods are that it will recover most ova, cysts and larvae and retain their morphology. ${ }^{18}$

Lack of knowledge about parasitic infections and poor cleanliness and hygiene can make children vulnerable for intestinal parasites. Children who do not use soap for handwashing were at higher odds of IPIs than children who use soap [adjusted odds ratio (aOR) 1.81]..$^{14}$ To tackle these chronic conditions among children in low- and middleincome countries, WHO has recommended an integral approach of proper sanitation, health education on hygiene and preventive chemotherapy. Although previous studies have explored the intestinal parasitic infections, ${ }^{14-25}$ few studies have used three methods in combination to determine the intestinal parasites, particularly in Southwestern Nepal.

\section{MATERIAL AND METHODS}

\section{Setting}

This study was conducted among children attending public and private schools in Bhairahawa. Most of the schools in Bhairahawa do not have sufficient latrine facilities and safe drinking water. While Nepal is progressing rapidly towards achieving open defecation free status including Bhairahawa, the water, sanitation and hygiene are poor.

\section{Participants}

A comparative cross-sectional study was conducted among primary school children of public and private schools of Bhairahawa from March 2019 to September 2019. A total of 408 stool samples were collected. Primary school children below age of 14 years with or without abdominal symptoms were included in the study.

\section{Data collection}

Students in the class were given a brief explanation about intestinal parasitic infections and the benefits of stool examination. Based on the consent forms, for sample collection dry and leak-proof containers which were devoid of antiseptics and disinfectants were provided and were advised to collect about a large teaspoon amount of faeces or $10 \mathrm{ml}$ in case of liquid stool. All the containers were labelled with the children's school identification number. During the distribution of containers, a semi-structured questionnaire 
recorded brief socio-demographic characteristics of the participants. Participants were advised not to mix stool with urine or water. Stool specimens were collected within the first hour of the school and were transported to Microbiology laboratory at UCMSTH immediately.

\section{Sample's processing}

Samples were examined for stool parasites macroscopically and microscopically. Both saline mount preparation and iodine mount preparation were examined under high power for routine microscopical examination to observe cyst, egg or larva in the stool. Both negative and positive samples were subjected to concentration techniques. Floatation technique was performed with the help of $33 \%$ of Zinc Sulphate solution whereas sedimentation technique was performed by formal ether concentration method.

\section{Data analysis}

Data from the Excel sheet were exported to IBM SPSS Statistics for Windows, Version 24.0, Armonk, NY: IBM Corp. Descriptive and inferential analysis were conducted to respond the research question. Significant association between independent and outcome variables were assessed by Chi-squared test with $p$ value $<0.05$.

\section{Ethical approval \& consent to participate}

Ethical approval was taken from Institutional Ethical Review Board of UCMSTH.

Ethical approval was taken from Institutional Ethical Review Board of UCMSTH. Case record forms for each participant was encoded to ensure the adequate anonymization and confidentiality. A written signed informed consent was obtained from each participant.

\section{RESULTS}

\section{Detection of parasites by various methods}

Out of 408 stool samples collected from students of different primary schools including public and private schools, 190 samples were found positive for parasites ( 95 were positive by routine microscopy, 34 by floatation and 170 samples were positive by sedimentation technique). Total 218 samples were found negative. The prevalence rate was $23.2 \%(95 / 408)$ by routine microscopy which increased to $46.5 \%$ (190/408) by concentration methods. Ascaris lumbricoides was the most prevalent parasite (29.1\%) followed by cyst of Entamoeba histolytica (6.1\%) and Giardia lamblia (6.1\%) (Figure 1 and Table 1).

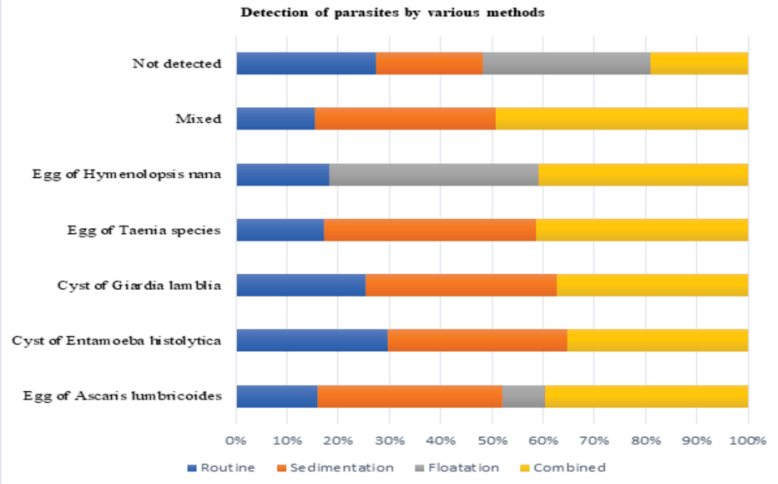

Figure 1. Prevalence of parasites using routine, sedimen tation, floatation and combination of all methods

Table 1. Frequency of parasites detected by three methods combined (routine, sedimentation and floatation)

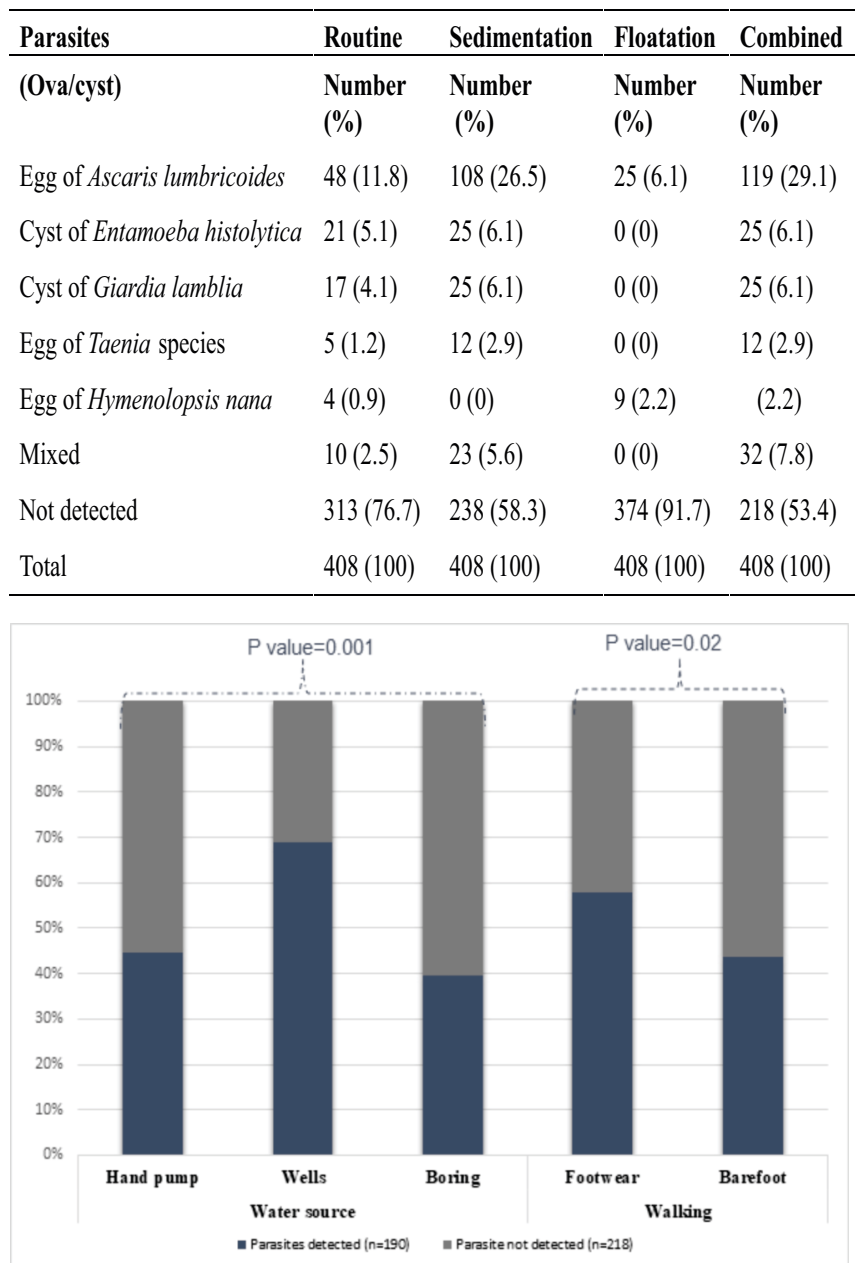

Figure 2. Drinking source of water and walking habit in relationship to detection of parasites

Socio-demographic characteristics and enteric parasitic infection 
Higher positivity rate was seen in class $1(61.5 \% ; 40 / 65)$ followed by class $2(59.1 \% ; 39 / 66)$. Occurrence of parasitic infection was highest $(52.1 \% ; 98 / 188)$ among the younger age group $(<9$ years of age).

Rate of the prevalence of the parasitic infection was associated with the specific age group (<9years) ( $p$-value $=0.101)$. Parasitic infection was detected slightly higher in male students $(47.3 \%)$ than female students $(45.7 \%)$. The prevalence of infection was highest among the children with BMI 13 to 15 (52.9\%). (Table 2)

Table 2. Socio-demographic characteristics and enteric parasitic infestation $(n=408)$

\begin{tabular}{|c|c|c|c|}
\hline Characteristics & $\begin{array}{l}\text { Parasites detected } \\
\text { ( } \mathrm{n}=190) \\
\text { Number }(\%)\end{array}$ & $\begin{array}{l}\text { Parasite not detected } \\
(\mathbf{n = 2 1 8 )} \\
\text { Number (\%) }\end{array}$ & p-value \\
\hline \multicolumn{4}{|l|}{ Class } \\
\hline Class 1 & $40(61.5 \%)$ & $25(38.4 \%)$ & 0.001 \\
\hline Class 2 & 39(59.1\%) & $27(40.9 \%)$ & \\
\hline Class 3 & $34(47.2 \%)$ & $38(52.8 \%)$ & \\
\hline Class 4 & $24(47.1 \%)$ & $27(52.9 \%)$ & \\
\hline Class 5 & $53(34.4 \%)$ & $101(65.6 \%)$ & \\
\hline \multicolumn{4}{|l|}{ Age } \\
\hline$<9$ years & $98(52.1 \%)$ & $90(47.9 \%)$ & 0.101 \\
\hline $10-11$ years & $71(42.8 \%)$ & $95(57.2 \%)$ & \\
\hline$>11$ years & $21(38.9 \%)$ & $33(61.1 \%)$ & \\
\hline \multicolumn{4}{|l|}{ Sex } \\
\hline Male & $105(47.3 \%)$ & $117(52.7 \%)$ & 0.276 \\
\hline Female & $85(45.7 \%)$ & $101(54.3 \%)$ & \\
\hline \multicolumn{4}{|l|}{ BMI } \\
\hline 12 and below & $22(44.9 \%)$ & $27(55.1 \%)$ & 0.101 \\
\hline $13-15$ & $112(52.9 \%)$ & $101(47.1 \%)$ & \\
\hline $16-18$ & $45(40.2 \%)$ & $67(59.8 \%)$ & \\
\hline $19-21$ & $8(32 \%)$ & $17(68 \%)$ & \\
\hline Above 21 & $3(33.3 \%)$ & $6(66.6 \%)$ & \\
\hline \multicolumn{4}{|l|}{ Family size } \\
\hline$<$ Five & $36(35.6 \%)$ & $65(64.4 \%)$ & 0.021 \\
\hline Five-Eight & $107(48.2 \%)$ & $115(51.8 \%)$ & \\
\hline$>$ Eight & $47(55.3 \%)$ & $38(44.7 \%)$ & \\
\hline \multicolumn{4}{|l|}{ Religion } \\
\hline Hindu & $152(44.6 \%)$ & $189(55.4 \%)$ & 0.323 \\
\hline Buddhist & $11(57.9 \%)$ & $8(42.1 \%)$ & \\
\hline Christian & $5(62.5 \%)$ & $3(37.5 \%)$ & \\
\hline Muslim & $22(55 \%)$ & $18(45 \%)$ & \\
\hline \multicolumn{4}{|l|}{ Ethnicity } \\
\hline Brahmin & $48(44.0 \%)$ & $61(56 \%)$ & 0.857 \\
\hline Janajati & $19(44.2 \%)$ & $24(55.8 \%)$ & \\
\hline Chhetri & $38(50 \%)$ & $38(50 \%)$ & \\
\hline Others & $85(47.2 \%)$ & $95(52.8 \%)$ & \\
\hline
\end{tabular}

\section{Hygiene related factors with enteric parasitic infestation}

Enteric parasitic infection was higher $(62.9 \%$; 51/81) among the children who had gastrointestinal upset within a week before collection of the stool sample ( $p$-value $=0.001)$ (Table 3 ). The place where children defecate was not strongly associated with the rate of parasite infection in them though $83.3 \%(5 / 6)$ of children who defecated in open space were infected by various parasite. Prevalence of parasites was higher $(69 \%$; 40/58) $(p=0.001)$ among those whose source of drinking water was wells (Figure 2). Children who had the habit of drinking water directly from the source had higher $(48.8 \% ; 158 / 324)$ parasitic infection. Parasitic infection was equally common among children irrespective of their status of domestic animals rearing at home. Higher rate of prevalence was seen among those children who had loose $(62.8 \% ; 22 / 35)$ stool sample. Public school children $(61.1 \% ; 99 / 162)$ were more prone to enteric parasitic infection as compared to the private school children $(37 \%$; $91 / 246)(<0.001)$.

Table 3. Hygiene related factors and enteric parasitic infections $(n=408)$

\begin{tabular}{|c|c|c|c|}
\hline Characteristics & \begin{tabular}{|l|}
$\begin{array}{l}\text { Parasites detected } \\
(n=190)\end{array}$ \\
\end{tabular} & $\begin{array}{l}\text { Parasite not detected } \\
(n=218)\end{array}$ & $p$-value \\
\hline \multicolumn{4}{|c|}{ Gastrointestinal upset } \\
\hline Yes & $51(62.9 \%)$ & $30(37.0 \%)$ & 0.001 \\
\hline No & $139(42.5 \%)$ & $188(57.5 \%)$ & \\
\hline \multicolumn{4}{|l|}{ Defecation } \\
\hline Toilet & $183(46.1 \%)$ & $214(53.9 \%)$ & 0.184 \\
\hline River bank & $2(40 \%)$ & $3(60 \%)$ & \\
\hline Open place & $5(83.3 \%)$ & $1(16.7 \%)$ & \\
\hline \multicolumn{4}{|l|}{ Water source } \\
\hline Hand pump & $100(44.6 \%)$ & $124(55.4 \%)$ & 0.001 \\
\hline Wells & $40(69 \%)$ & $18(31 \%)$ & \\
\hline Boring & $50(39.7 \%)$ & $76(60.3 \%)$ & \\
\hline \multicolumn{4}{|l|}{ Drinking water } \\
\hline Direct & $158(48.8 \%)$ & $166(51.2 \%)$ & 0.166 \\
\hline Boiling & $7(46.7 \%)$ & $8(53.3 \%$ & \\
\hline Filtration & $25(36.2 \%)$ & $44(63.7 \%)$ & \\
\hline \multicolumn{4}{|l|}{ Veg/Non-veg } \\
\hline Veg & $32(48.5 \%)$ & $34(51.5 \%)$ & 0.733 \\
\hline Non-veg & $158(46.2 \%)$ & $184(53.8 \%)$ & \\
\hline \multicolumn{4}{|c|}{ Domestic animal rearing } \\
\hline Yes & $161(46.5 \%)$ & $185(53.5 \%)$ & 0.972 \\
\hline No & $29(46.8 \%)$ & $33(53.2 \%)$ & \\
\hline \multicolumn{4}{|l|}{ Deworming } \\
\hline 3 months ago & $185(47.5 \%)$ & $204(52.4 \%)$ & 0.187 \\
\hline 1 month ago & $4(25 \%)$ & $12(75 \%)$ & \\
\hline last week & $1(33.3 \%)$ & $2(66.6 \%)$ & \\
\hline \multicolumn{4}{|l|}{ Walking bare foot } \\
\hline Yes & $48(57.8 \%)$ & $35(42.2 \%)$ & 0.021 \\
\hline No & $141(43.7 \%)$ & $182(56.3 \%)$ & \\
\hline \multicolumn{4}{|l|}{ Nail cut/week } \\
\hline Twice & $34(43.0 \%)$ & $45(57.0 \%)$ & 0.398 \\
\hline once & $139(46.5 \%)$ & $160(53.5 \%)$ & \\
\hline once in two weeks & $17(58.6 \%)$ & $12(41.4 \%)$ & \\
\hline No cut & $0(0 \%)$ & $1(100 \%)$ & \\
\hline \multicolumn{4}{|c|}{ Consistency of stool } \\
\hline Formed & $54(47 \%)$ & $61(53 \%)$ & 0.115 \\
\hline Semi-formed & $114(44.2 \%)$ & $144(55.8 \%)$ & \\
\hline Loose & $22(62.8 \%)$ & $13(37.2 \%)$ & \\
\hline \multicolumn{4}{|l|}{ School } \\
\hline Public & $99(61.1 \%)$ & $63(38.9 \%)$ & $<0.001$ \\
\hline Private & $91(37 \%)$ & $155(63 \%)$ & \\
\hline
\end{tabular}

\section{DISCUSSION}

\section{Overview}

The intestinal parasitic infection among the school children is one of the major global public health problems. ${ }^{3,14}$ Protozoan such as Entamoeba histolytica, Giardia lamblia and helminthes such as Ascaris lumbricoides, Taenia spp, 
Ancylostoma dudonale and Hymenolepis nana are the major parasites causing intestinal infections in Nepal. ${ }^{14}$

\section{Detection of parasites by various methods}

The overall prevalence of parasitic infection was $46.4 \%$ which is higher than the same type of cross- sectional study conducted in the Kaski district in $2014^{23}$ and Kathmandu in $2013 .^{21}$ The most common parasites detected in this research were Ascaris lumbricoides (29.1\%), Entamoeba histolytica (6.1\%), G. lamblia (6.1\%), Taenia spp (2.9\%) and H. nana (4.2\%). Similar study carried out in Rupandehi District in 2016 found $60 \%$ of parasitic infection, ${ }^{22}$ which is slightly higher than our study. Since 2016, the District has changed drastically with regards to sanitation and sewage disposal. Economical and educational status has improved substantially which might be one of the reasons for declining parasitic infection in the district. Ascaris lumbricoides was the most common parasite detected which is $80 \%$ out of the positive cases $^{22}$ which is still the commonest parasite.

Surprisingly, there was no any egg of Ancyclostoma duodenale detected in our study. However, in Morang, 44.5\% of the samples showed Ancyclostoma duodenale. ${ }^{24}$ People in Morang district rely on the subsistence farming for livelihood, and children generally accompany barefoot with their parents to the field which might be one of the reasons for high incidence of hookworm infection. ${ }^{25}$

\section{Socio-demographic characteristics and enteric parasitic infection}

In Birgunj, the prevalence of the parasitic infection was found highest among the children of $\leq 5$ years ${ }^{17}$ which is consistent with our study. Rate of prevalence of the enteric parasitic infection was slightly higher among the male students. A study from Kathmandu valley in 2018 showed higher prevalence among the female students $(70.8 \%)^{6}$

Prevalence of the enteric parasite was higher among those children whose BMI ranges from 13 to 15 which is consistent with the past study conducted in Rupandehi. ${ }^{22}$ Similarly, prevalence of the enteric parasitic infection was higher among the children who belonged to Chhetri ethnicity (50\%). However, higher prevalence of enteric parasites among Dalit group was found in a previous study conducted in $2016 .^{25}$

\section{Hygiene related factors with enteric parasitic infestation}

This study showed that the rate of prevalence of parasitic infection was higher among the symptomatic children and is consistent with a study conducted in Kathmandu in $2018 .{ }^{6}$ However, another study conducted in Rupandehi district in 2016 showed that enteric parasitic infection was more common among the asymptomatic children. ${ }^{22}$ The findings of this study reconfirms that the prevalence of enteric parasitic infection was high among the students who defecated in open spaces. The association between open defecation zones and enteric parasitic infections was found in Gujarat. ${ }^{11}$ While government's efforts in expanding open defecation free zones are underway, regular screening and mass de-worming could be planned to ensure children are free from the enteric parasitic infections. Prevalence of the parasitic infection was higher among the children whose source of drinking water was wells $(69 \%)$. A study conducted in Kathmandu showed higher prevalence among those who used direct tap water as the main source of drinking water $(45.9 \%){ }^{22}$ Prevalence of the intestinal parasitic infection was higher among those students who did not practice good hygiene such as not cutting nails once in two weeks $(58.6 \%)$, which is consistent with the study done among primary school children in Kathmandu valley in $2014(62.81 \%)^{25}$

\section{Public school versus private school}

Another important finding of our study was that public school children $(61.1 \%$; 99/162) were more prone to enteric parasitic infection as compared to the private school children (40\%; 91/246). This finding is consistent with the finding from a study conducted in Kathmandu valley. ${ }^{6}$ In Nepal, public schools mainly aim to provide primary education to children who come from socio-economically poor families. Children from the lower socio-economical class and attending public schools also lack adequate education about safe drinking water and are deprived from proper sanitation and hygiene and may have been the reasons for high parasitic infestation.

\section{CONCLUSION}

Despite that de-worming is conducted frequently in schools, the rate of prevalence of the enteric parasitic infection is high among the students under 14 years of age. Public school children have slightly higher rate of enteric parasitic infection than private school children. Concentration techniques are essential for the detection of greater number of enteric parasites in stool specimens. The rate of detection of the parasites increased by two-fold after performing concentration techniques, both sedimentation and floatation methods.

\section{CONFLICT OF INTEREST}

None

\section{ACKNOWLEDGEMENTS}

We would like to express our gratitude to all the participating schools and children who provided their stool sample for this study. 


\section{REFERENCES}

1. Bethony J, Brooker S, Albonico M, Geiger SM, Loukas A, Diemert D, Hotez PJ: Soil-transmitted helminth infections: ascariasis, trichuriasis, and hookworm. Lancet. 2006;367 :1521-1532.

2. WHO. Fact sheet, soil-transmitted helimnth infections. https://www.who.int/en/news-room/fact-sheets/detail/soiltransmitted-helminth-infec tions. Accessed 20 May 2021

3. Hotez PJ, Alvarado M, Basanez MG, Bolliger I, Bourne R, Boussinesq M, Brooker SJ, Brown AS, Buckle G, Budke CM, et al. The global burden of disease study 2010: interpretation and implications for the neglected tropical diseases. PLoS Negl Trop Dis. 2014;8:e2865.

4. Pullan RL, Smith JL, Jasrasaria R, Brooker SJ. Global numbers of infection and disease burden of soil transmitted helminth infections in 2010. Parasites \& vectors. 2014;7:1-19.

5. Rai SK: Changing trend of infectious diseases in Nepal. Infectious Diseases and Nanomedicine III.2018;1052:19-38.

6. Dahal C, Katwal P, Thapa A, Sharma D, Khadka R: Intestinal parasitosis among the school children of Kathmandu, Nepal. Tribhuvan University Journal of Microbiology. 2018;5:89-96.

7. Haque R: Human intestinal parasites. Journal of Health, Population, and Nutrition. 2007;25:387.

8. Prasad K: Emerging and re-emerging parasitic diseases. J Int Med Sci Acad. 2010;23:45-50.

9. Ahir H, Patel P, Nerurkar A: Intestinal parasitic infections in patients attending tertiary care hospital, Valsad, South Gujarat, India: A retrospective study. J Pharm Biomed Sci. 2015;5:117121.

10. Khanal L, Rai S, Khanal P, Ghimire G: Status of intestinal parasitosis among hospital visiting patients in Deukhury Valley, Dang, Nepal. Nepal Medical College Journal: NMCJ. 2011;13:100-102.

11. Pandya HB, Lakhani SJ, Pandit N, Hemachander SS. Prevalence and risk factors associated with intestinal parasitic infestations in the rural pediatric population of Piparia, Gujarat-A hospital-based study. International Journal of Medical Science and Public Health.2017;6(10):1498-1502.

12. Toro-Londono MA, Bedoya-Urrego K, Garcia-Montoya GM,et al. Intestinal parasitic infection alters bacterial gut microbiota in children. Peer J. 2019; 7:e6200.

13. Rituparna B, Bhattacharya P, Paul U, Bandyopadhyay A: Prevalence of intestinal parasites in a tertiary care hospital in rural Bihar. Int J Sci Stud. 2017;4:89-93.

14. Shrestha A, Schindler C, Odermatt P, Gerold J, Erismann S, Sharma S, Koju R, Utzinger J, Cissé G. Intestinal parasite infections and associated risk factors among schoolchildren in Dolakha and Ramechhap districts, Nepal: a cross-sectional study. Parasites \& vectors. 2018;11:1-15.
15. Gupta R, Rayamajhee B, Sherchan SP, Rai G, Mukhiya RK, Khanal B, Rai SK. Prevalence of intestinal parasitosis and associated risk factors among school children of Saptari district, Nepal: a cross-sectional study. Trop Med Health. 2020;48:73.

16. Tiwari BR, Chaudhary R, Adhikari N, Jayaswal SK, Poudel TP, Rijal KR: Prevalence of intestinal parasitic infections among school children of Dadeldhura District, Nepal. Journal of Health and Allied Sciences. 2013;3:14-16.

17. Shakya B, Shrestha S, Madhikarmi N, Adhikari R: Intestinal parasitic infection among school children. J Nepal Health Res Counc. 2012 Jan;10(1):20-3.

18. Agrawal P, Rai S, Khanal L, Ghimire G, Banjara M, Singh A: Intestinal parasitic infections among patients attending Nepal Medical College Teaching Hospital, Kathmandu, Nepal. Nepal Medical College Journal: NMCJ. 2012;14:80-83.

19. Chandrashekhar T, Joshi H, Gurung M, Subba S, Rana M, Shivananda P: Prevalence and distribution of intestinal parasitic infestations among school children in Kaski District, Western Nepal. Journal of Medicine and Biomedical Research. 2005;4(1):78-82.

20 Sah RB, Bhattarai S, Yadav S, Baral R, Jha N, Pokharel PK. A study of prevalence of intestinal parasites and associated risk factors among the school children of Itahari, Eastern Region of Nepal. Tropical parasitology. 2013;3:140.

21. Pandey S, Lo AL, Shrestha RB: Intestinal parasitic infections among school children of Northern Kathmandu, Nepal. Asian Pacific Journal of Tropical Disease. 2015;5:S89-S92.

22. Khanal R, Upadhaya S, Lamichhane P, Karn SL, Pokhrel S, Pahwa V. Enteric parasitic infections among school children at Rupandehi, Nepal. Journal of Universal College of Medical Sciences. 2016;4:30-34

23. Jaiswal S, Pant DR, Tiwari BR, Sah JP, Bhandari R, Upadhyaya S: Prevalence of intestinal parasite among school children of Bharatpokhari VDC, Kaski, Nepal. Microbiology Research Journal International. 2014:1007-1012.

24. Yadav SN, Mahato S: Study on intestinal helminth parasites in school children of Rangeli Municipality of Morang District in Eastern Nepal. American Journal of Health Research. 2017, 5:50-53.

25. Yadav K, Prakash S: Study of intestinal Parasitosis among school children of Kathmandu Valley, Nepal. Asian Journal of Biomedical and Pharmaceutical Sciences. 2016;6(59):40-47. 